\title{
Phytoremediation Potential of Sorghum as a Biofuel Crop and the Enhancement Effects with Microbe Inoculation in Heavy Metal Contaminated Soil
}

\author{
Kokyo Oh${ }^{1}$, Tiehua Cao ${ }^{2}$, Hongyan Cheng 3 , Xuanhe Liang2, Xuefeng Hu${ }^{4}$, Lijun Yan ${ }^{4}$, \\ Shinichi Yonemochi ${ }^{1}$, Sachiko Takahi ${ }^{5}$ \\ ${ }^{1}$ Center for Environmental Science in Saitama, Kazo, Japan \\ ${ }^{2}$ Center of Resource and Environmental Science, Jilin Academy of Agricultural Sciences, Changchun, China \\ ${ }^{3}$ College of Resources and Environment, Shanxi Agricultural University, Taigu, Shanxi, China \\ ${ }^{4}$ School of Environmental and Chemical Engineering, Shanghai University, Shanghai, China \\ ${ }^{5}$ Faculty of Education and Human Studies, Akita University, Akita, Japan \\ Email: ${ }^{*}$ caotiehua2002@163.com
}

Received April 2015

\begin{abstract}
Phytoremediation is an eco-friendly and low-cost biotechnology using plants to extract, contain, degrade, or immobilize pollutants from the contaminated environment. Selection of the ideal plant species and suitable enhancing measures to obtain high remediation efficiency and large valuable biomass are essential requirement for a successful phytoremdaition. Sorghum (Sorghum bicolor L.) is one of the most attractive bioenergy crops for producing biofuels with high biomass production. In this study, the phytoremediation potential of sorghum to heavy metals and the promotion effects by a lead-tolerant fungus (LTF) were investigated using a multiple heavy metal contaminated soil with $\mathrm{Pb}, \mathrm{Ni}$, and $\mathrm{Cu}$. The results showed that the sorghum survived the heavy contamination, and LTF inoculation promoted the plant growth and increased the phytoextraction yields of $\mathrm{Pb}, \mathrm{Ni}$, and $\mathrm{Cu}$. The phytoextraction potential $(\mu \mathrm{g} / \mathrm{plant})$ of the whole sorghum for Sorghum were $410(\mathrm{~Pb}), 74(\mathrm{Ni})$, and $73(\mathrm{Cu})$, and for Sorghum with LTF inoculation were $590(\mathrm{~Pb})$, $120(\mathrm{Ni})$, and $93(\mathrm{Cu})$, respectively. The results suggested that sorghum would be one of the ideal candidates for phytoremediation of contaminated soil because of its high phytoremediation potential, large biomass production, and utilization in biofuel production.
\end{abstract}

\section{Keywords}

Sorghum, Phytoremediation, Contaminated Soil, Heavy Metals, Biofuel Plants

\footnotetext{
"Corresponding author.

How to cite this paper: Oh, K., Cao, T.H., Cheng, H.Y., Liang, X.H., Hu, X.F., Yan, L.J., Yonemochi, S. and Takahi, S. (2015) Phytoremediation Potential of Sorghum as a Biofuel Crop and the Enhancement Effects with Microbe Inoculation in Heavy Metal Contaminated Soil. Journal of Biosciences and Medicines, 3, 9-14. http://dx.doi.org/10.4236/jbm.2015.36002
} 


\section{Introduction}

Phytoremediation, an emerging technology that uses various plants to extract, contain, or immobilize contaminants from soil, has been received increasing attention as an innovative, cost-effective alternative method for remediation of contamination soil [1] [2]. Phytoremediation can remove heavy metals from soil and improve soil quality [3].

However, as plants usually grow slowly, phytoremediation usually has a low efficiency and generally needs many years to achieve a good remediate effect, which greatly limits the practical application of phytoremediation [1] [4]. In order to promote the application of phytoremediation, we focus on searching ideal plant species with high extraction ability of heavy metals, high biomass production, and high economic values [5]. In this way, we can guarantee the economic income for the owner of the contamination sites during the remediation period, thus, the practical application of phytoremediation can be promoted [6]. On the other hand, to improve the remediation efficiency, we are also studying on means for enhancing phytoremdiation through application of chelating agents and effective bacteria [7].

Sorghum (Sorghum bicolor L.) is a plant with high tolerance to diverse growing conditions, high biomass production, various processes for bioenergy production, and low nitrogen fertilizer requirements. Therefore, in this study we determined the potential of sorghum for phytoremediation of multiple heavy metal contaminated soil, and the promotion effects on phytoremediation potential by a lead-tolerance fungous isolated from lead contaminated soil.

\section{Materials and Methods}

The pot cultural experiment was conducted in the green house in Changchun city of China, with natural photoperiod, temperature around $25^{\circ} \mathrm{C}$ in the day time and $21^{\circ} \mathrm{C}$ at night, and relative air humidity of about $70 \%$. The soil used in the experiment was a loam soil contaminated by $\mathrm{Pb}, \mathrm{Ni}$ and $\mathrm{Cu}$, with $\mathrm{pH}$ of 7.2 (Table 1). Prior to filling into pots, the soil was air dried, ground, and homogenously mixed. $20 \mathrm{~kg}$ of the soil was filled in each pot for growing sorghum.

Sorghum variety Siza 25 was used in this study. Five seeds of the sorghum were sown in the contaminated soil, and after three weeks of germination, one plant per pot was selected for harvest at last. Two treatments, sorghum (SG) and sorghum with microbe inoculation (SGM), were conducted with three replications.

The microbe used in this study was a lead-tolerant fungus (LTF), a rhizobacterial isolate (ZJ1 Isolate) isolated from $\mathrm{Pb}$ contaminated soil, which has been proved to be able to promote $\mathrm{Pb}$ uptake by ryegrass [8]. The inoculation of the microbe was done by pouring the bacterial cultural solution to the soil. The plants were watered daily to avoid water stress. Three replicates of each treatment were removed from the green house in the harvest day.

After harvest, root, stem, leaf and grain were carefully separated, washed, weighted and oven dried at $70^{\circ} \mathrm{C}$ for 48 hours for determining the plant dry biomass and the heavy metal contents.

The dried plant samples were granted by a mill and then mixed evenly for heavy metal analysis. Plant samples were digested using concentrated $\mathrm{HNO}_{3}$ and $\mathrm{H}_{2} \mathrm{O}_{2}$, dissolved with 1:1 $\mathrm{HNO}_{3}$, filtered with filter paper, and transfer to flask for ICP-MS determination of the $\mathrm{Pb}, \mathrm{Ni}$ and $\mathrm{Cu}$ concentrations.

Phytoremediation potential was evaluated with phtoextraction potential, which was described as the total amount of heavy metal extracted by per plant in a single harvest cycle, and the following Formula (1) was used for calculation phtoextraction potential (PEP).

$$
P E P=C_{\text {plant }} \times M_{\text {plant }}
$$

where, $C_{\text {plant }}$ is the metal concentration in plant, $M_{\text {plant }}$ is the dry weight of the plant biomass [9].

Table 1. Contents of heavy metals in soil and crop (mg/kg).

\begin{tabular}{ccccc}
\hline & $\mathrm{pH}$ & $\mathrm{Pb}$ & $\mathrm{Ni}$ & $\mathrm{Cu}$ \\
\hline Testing soil & 7.15 & 556 & 140 & 31.9 \\
National standard (soil) & $6.5<\mathrm{pH}<7.5$ & 300 & 50 & 100 \\
\hline
\end{tabular}




\section{Results and Discussion}

\subsection{Plant Biomass Production}

Sorghum in each pot grew well with green colored leaves, and no visible physical damage showing toxicity symptoms was found at all plants. As shown in Figure 1, the total biomass dry weight of individual sorghum plant for SG and SGM treatments were 81.5 and 98.6, while the grain biomass were 35.2 and $48.9 \mathrm{~g} / \mathrm{plant}$, respectively. Microbe inoculation showed $21 \%$ increase in total biomass production and $44 \%$ in grain production. SGM treatment also showed some increasing effect on root and stem biomass, however, no positive effect was found in leaves.

These results indicated that the sorghum had good tolerance to the multiple heavy metal soil contamination with $\mathrm{Pb}, \mathrm{Ni}$ and $\mathrm{Cu}$. The results were supported by the findings in other studies, which reported that sorghum had high tolerance to the heavy metal stress [10] [11].

The results also showed the microbe inoculation promoted sorghum growth and biomass production, with the highest increasing rate to grain yield compared with the sorghum without microbe inoculation. This indicated that the microbe used in this study was a plant growth promoting bacterium. The increase in grain yield can generate more economic income from the contaminated soil when the grain is used for producing bioenergy, which is important for sustainability of phytoremediation.

\subsection{Heavy Mental Concentrations in Different Plant Organs}

The concentrations of $\mathrm{Pb}$ in different parts of sorghum were quite different, with a general trend from high to low of root $>$ leaf $>$ shoot $>$ grain. Compared with SG treatment, SGM treatment weakly increased Pb concentration of roots (increased by 25\%), but little increase was found in stem, leaf and grain (Table 2).

The content of $\mathrm{Ni}$ had a similar trend with that of $\mathrm{Pb}$. The concentration in different organs also had a high to low trend of root $>$ leaf $>$ shoot $>$ grain. Microbe inoculation increased $50 \%$ in Ni content in roots, but little increase effect was found in stem, leaf, and grain (Table 3).

The performance of $\mathrm{Cu}$ concentration (Table 4) in the sorghum had some difference with $\mathrm{Pb}$ and $\mathrm{Ni}$. Although $\mathrm{Cu}$ content in roots is the highest, the contents in stem and leaf were at a same level. Cu concentration in roots was much lower than that of $\mathrm{Pb}$ and $\mathrm{Ni}$, however, it is much higher in grain than that of $\mathrm{Pb}$ and $\mathrm{Ni}$, which possibly caused by the higher mobility of $\mathrm{Cu}$ in plant compared with $\mathrm{Pb}$ and $\mathrm{Ni}$.

Not like some hyperaccumulator (the plants capable of growing in soils with very high concentrations of metals, absorbing these metals through their roots, and concentrating extremely high levels of metals in their tissues) such as Indian mustard and Chinese brake fern [12], the concentrations of $\mathrm{Pb}, \mathrm{Ni}$ and $\mathrm{Cu}$ in sorghum were at the range of normal levels [13]. No extremely high heavy metal levels in all the organs of the sorghum. $\mathrm{Pb}, \mathrm{Ni}$ and $\mathrm{Cu}$ concentration in the grain were much lower than stem and leaf, and nearly the same level as that harvested in the uncontaminated farmland, so there would be no influence for the use of bioenergy i.e. bioethanol.

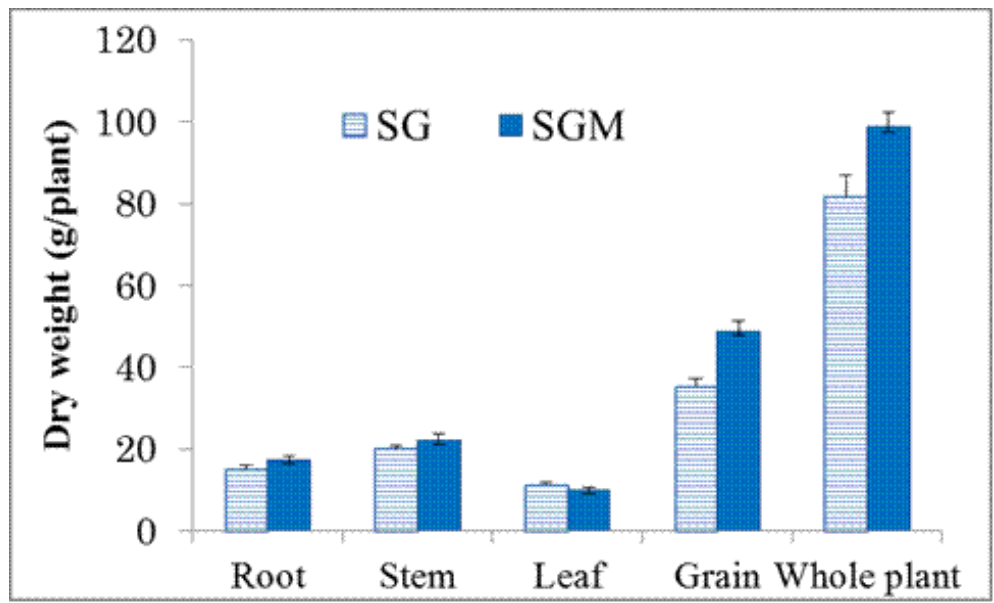

Figure 1. Biomass of individual sorghum plant with and without microbe inoculation 
Table 2. Contents of $\mathrm{Pb}$ in different organs of sorghum (mg/kg).

\begin{tabular}{ccccc}
\hline Treatments & Root & Stem & Leaf & Grain \\
\hline SG & $210.1 \pm 1.81$ & $13.0 \pm 0.67$ & $35.0 \pm 1.57$ & $2.56 \pm 0.17$ \\
SGM & $278.8 \pm 13.4$ & $10.5 \pm 0.70$ & $36.4 \pm 2.52$ & $3.33 \pm 0.46$ \\
\hline
\end{tabular}

Table 3. Contents of Ni in different organs of sorghum (mg/kg).

\begin{tabular}{ccccc}
\hline Treatments & Root & Stem & Leaf & Grain \\
\hline SG & $40.5 \pm 1.23$ & $1.41 \pm 0.15$ & $3.63 \pm 0.21$ & $0.80 \pm 0.05$ \\
SGM & $60.6 \pm 1.38$ & $1.38 \pm 0.18$ & $3.78 \pm 1.83$ & $0.92 \pm 0.12$ \\
\hline
\end{tabular}

Table 4. Contents of $\mathrm{Cu}$ in different organs of sorghum (mg/kg).

\begin{tabular}{ccccc}
\hline Treatments & Root & Stem & Leaf & Grain \\
\hline SG & $19.8 \pm 1.60$ & $7.15 \pm 0.07$ & $7.56 \pm 0.45$ & $4.95 \pm 0.38$ \\
SGM & $20.6 \pm 0.87$ & $7.74 \pm 0.19$ & $8.02 \pm 0.30$ & $5.68 \pm 0.38$ \\
\hline
\end{tabular}

The results obtained showed much variation in heavy metal concentrations, following the sequence $\mathrm{Pb}>\mathrm{Ni}>$ $\mathrm{Cu}$ in roots, $\mathrm{Pb}>\mathrm{Cu}>\mathrm{Ni}$ in stems, and $\mathrm{Cu}>\mathrm{Pb}>\mathrm{Ni}$ in grains, respectively. This sequence in roots showed reflectiveness of the total content of heavy metals in the soil. LTF inoculation increased the Pb and Ni concentration in roots. However, we did not find promotion effect on heavy metal concentration of sorghum in shoots (stem, leaf, and grain) with LTF inoculation. Different from $\mathrm{Ni}$ and $\mathrm{Pb}$, the results showed a light increase in $\mathrm{Cu}$ concentrations in roots, stems, leaves and grains with inoculation of LTF. The heavy metal concentration in stems, leaves, and grains seemed mainly influenced by the translocation properties of heavy metal from root to shoot. Cu showed higher translocation ability from root to stem, leaves and grains than $\mathrm{Ni}$ and $\mathrm{Pb}$.

\subsection{Phytoremediation Potential}

In the process of phytoremediation, heavy metals are removed from soils by harvesting plants. So, phytoremediation potential of plants to soil heavy metals is generally decided by the heavy metal accumulation amount of plants from soil during one harvesting cycle. The mean values of accumulation rates (phytoremediation potential) of $\mathrm{Pb}, \mathrm{Ni}$ and $\mathrm{Cu}$ by individual sorghum plant are shown in Figure 2. Results showed that in the SG treatment accumulation rates of $\mathrm{Pb}, \mathrm{Ni}$ and $\mathrm{Cu}$ by the whole plant of sorghum were 3900, 705, and $700 \mu \mathrm{g} / \mathrm{plant}$, respectively. Results also showed that $81 \%$ of $\mathrm{Pb}$ and $86 \%$ of $\mathrm{Ni}$ were accumulated in the roots, respectively. Unlike $\mathrm{Pb}$ and $\mathrm{Ni}$, only $42 \%$ of $\mathrm{Cu}$ was accumulated in the root, indicating $\mathrm{Cu}$ had much higher translocation rate from root to shoot than $\mathrm{Pb}$ and $\mathrm{Ni}$. Mohebbi (2012) also reported that $\mathrm{Cu}$ had higher translocation rate than $\mathrm{Pb}$ in alfalfa [14]. High translocation rate from root to shoot were important for phytoremediation as the heavy metals was uptake to the easily harvestable plant parts i.e. shoot.

Compared to the SG treatment, SGM gave promotion to heavy metal accumulation rates in the whole plant, with increasing rates of $45 \%(\mathrm{~Pb}), 66 \%(\mathrm{Ni})$, and $27 \%(\mathrm{Cu})$, respectively. For $\mathrm{Pb}$ and $\mathrm{Ni}$, the accumulation increase was almost from root, whereas for $\mathrm{Cu}$, the increase was from both root and shoot (Figure 2).

It is reported that the most suitable plantation density of the sorghum was 105,000 plants/ha [15]. Based on this plantation density, we made an estimation for the phytoextraction yields of the three heavy metals in shoot (above ground part) and whole plant (Table 5). As shown in Table 5, phytoextraction yileds (g/ha) by the whole sorghum for SG were $410(\mathrm{~Pb}), 74(\mathrm{Ni})$, and $73(\mathrm{Cu})$, and for SGM were $590(\mathrm{~Pb}), 120(\mathrm{Ni})$, and $93(\mathrm{Cu})$, respectively. However, phytoextraction yields by shoot were much lower, with small variation between SG and SGM. Our data of phytoextraction yields were lower for $\mathrm{Cu}$ but higher for $\mathrm{Pb}$ than the data reported by Marchiol et al. (2010), in which sorghum removed $820 \mathrm{~g} / \mathrm{ha}$ for $\mathrm{Cu}$ and $107 \mathrm{~g} / \mathrm{ha}$ for $\mathrm{Pb}$. The reason possibly was that in the current study, the soil $\mathrm{Pb}$ concentration was much higher than $\mathrm{Cu}$ [16].

The current study showed that more $\mathrm{Pb}, \mathrm{Ni}$ and $\mathrm{Cu}$ were accumulated by sorghum in SGM treatment, indicating that the LTF promoted phytoextraction to the three heavy metals by sorghum. The increase in accumulation 

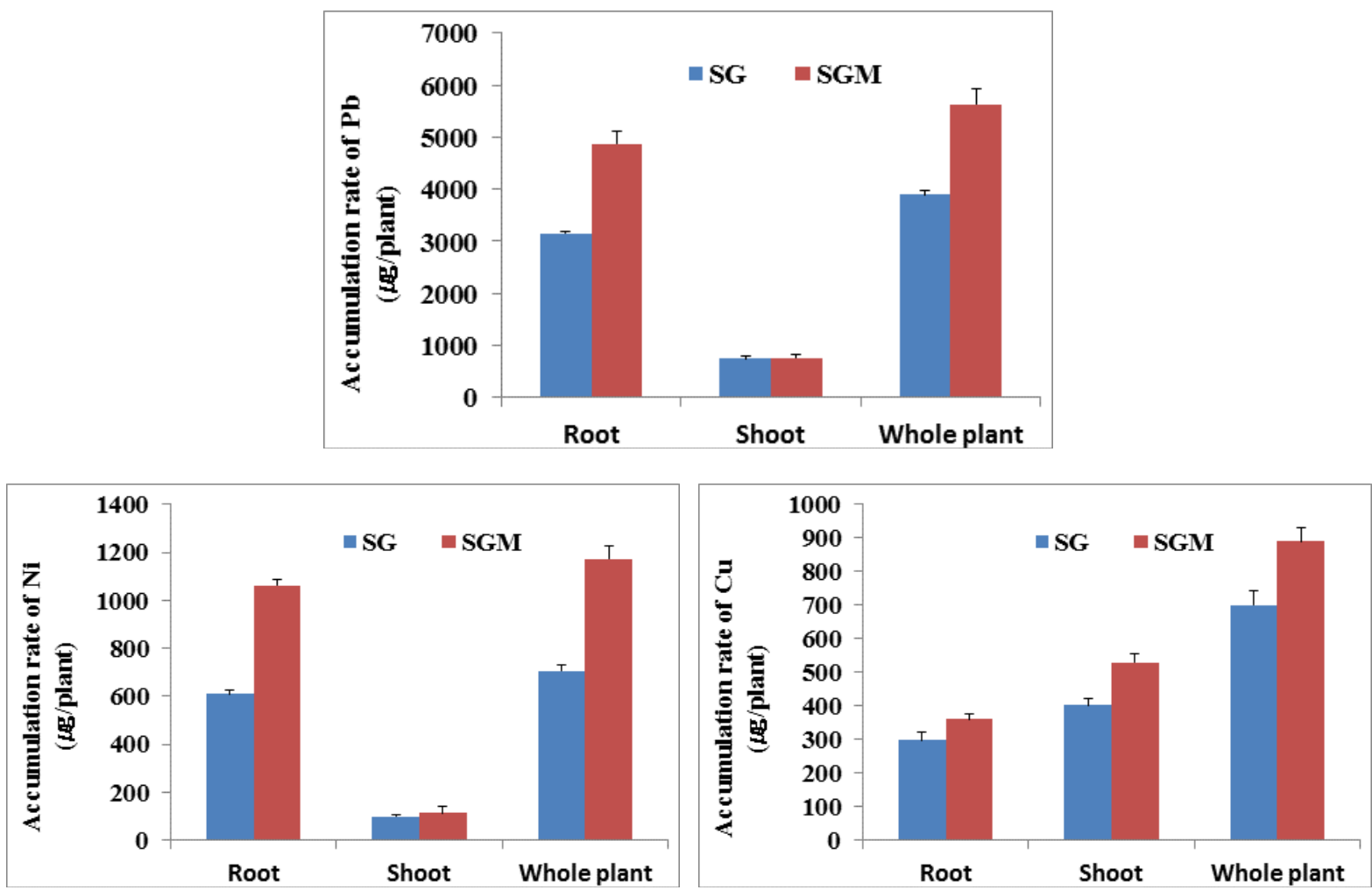

Figure 2. The accumulation rates of $\mathrm{Pb}, \mathrm{Ni}$ and $\mathrm{Cu}$ in different parts of plants.

Table 5. Estimation of phytoextraction yields of $\mathrm{Pb}, \mathrm{Ni}$ and $\mathrm{Cu}$ by sorghum (g/ha) based on a plantation density of 105,000 plant/ha.

\begin{tabular}{ccccccc}
\hline \multirow{2}{*}{ Treatments } & \multicolumn{2}{c}{$\mathrm{Pb}$} & \multicolumn{2}{c}{$\mathrm{Ni}$} & \multicolumn{2}{c}{$\mathrm{Cu}$} \\
\cline { 2 - 7 } & Shoot & Whole plant & Shoot & Whole plant & Shoot & Whole plant \\
\hline SG & 78 & 410 & 10 & 74 & 42 & 73 \\
SGM & 80 & 590 & 12 & 120 & 56 & 93 \\
\hline
\end{tabular}

of $\mathrm{Pb}, \mathrm{Ni}$ and $\mathrm{Cu}$ with LTF inoculation was mainly contributed by promotion of plant growth and heavy metal concentration in the root of sorghum.

\section{Conclusions}

This study detected that the sorghum grew normally without suffering any visible phytotoxicity in the multiple metal contaminated soil. The sorghum also had considerable accumulation ability to $\mathrm{Pb}, \mathrm{Ni}$ and $\mathrm{Cu}$ in root and shoot. The concentration of $\mathrm{Pb}, \mathrm{Ni}$ and $\mathrm{Cu}$ in grains still belonged to the normal range, which should be suitable for biofuel production.

Inoculation of LPF effectively increased $\mathrm{Pb}, \mathrm{Ni}$ and $\mathrm{Cu}$ phytoextraction potential of sorghum. The increase of phytoextraction potential with LPF inoculation was contributed from promotion to biomass production and heavy metal concentration in root of sorghum. Anyway, there was a need of further study on the mechanism of this LPF in promotion to the growth and heavy metal uptake in the roots of sorghum.

The accumulation mass of heavy metal from soil, biomass production and its economic values were three major factors for selecting the plants for phytoremediation. From this study, we could conclude that the sorghum Siza24 could be considered an energy crop extremely suitable for remediation and utilization of heavy metal contaminated soil. The LPF used in this study could act as a phytoextraction enhancer for sorghum in remediation of heavy metal contaminated soils, although its promotion mechanisms and the suitable application rate 
need further study.

\section{Acknowledgements}

This work was supported by Jilin Agricultural Science and Technology Innovation Project (No. 2013007), Shanxi International Cooperation Project (2013081002), the National Natural Science Foundation of China (41130526), and the JSPS KAKENHI (No. 23405049, 25301001).

\section{References}

[1] Oh, K., Li, T., Cheng, H., Xie, Y. and Yonemochi, S. (2013) Study on Tolerance and Accumulation Potential of Biofuel Crops for Phytoremediation of Heavy Metals. International Journal of Environmental Science and Development, 4 , 152-156. http://dx.doi.org/10.7763/IJESD.2013.V4.325

[2] EPA (2000) Introduction to Phytoremediation. EPA/600/R-99/107.

[3] Jiang, C.Y., Sheng, X.F., Qian, M. and Wang, Q.Y. (2008) Isolation and Characterization of a Heavy Metal-Resistant Burkholderia sp. from Heavy Metal-Contaminated Paddy Field Soil and Its Potential in Promoting Plant Growth and Heavy Metal Accumulation in Metal-Polluted Soil. Chemosphere, 72, 157-164. http://dx.doi.org/10.1016/j.chemosphere.2008.02.006

[4] Oh, K., Li, T., Cheng, H.Y., Hu, X., Lin, Q. and Xie, Y. (2013) A Primary Study on Assessment of Phytoremediation Potential of Biofuel Crops in Heavy Metal Contaminated Soil. Applied Mechanics and Materials, 295-298, 1135-1138. http://dx.doi.org/10.4028/www.scientific.net/AMM.295-298.1135

[5] Oh, K., Cao, T., Li, T. and Cheng, H. (2014) Study on Application of Phytoremediation Technology in Management and Remediation of Contaminated Soils. Journal of Clean Energy Technology, 2, 216-220. http://dx.doi.org/10.7763/JOCET.2014.V2.126

[6] Chintakovid, W., Visoottiviseth, P., Khokiattiwong, S. and Lauengsuchonkul, S. (2008) Potential of the Hybrid Marigolds for Arsenic Phytoremediation and Income Generation of Remediators in Ron Phibun District, Thailand. Chemosphere, 70, 1532-1537. http://dx.doi.org/10.1016/j.chemosphere.2007.08.031

[7] Li, T., Cheng, H., Oh, K., et al. (2013) Effect of Humic Acid and Bacterial Manure on Distribution of Heavy Metals in Different Organs of Maize. International Journal of Environmental Science and Development, 5, 393-397.

[8] Cao, T.H., Mu, Z.S., Wang, S.P., Yan, H.Y., Liang, X.H., Fan, Z.W. and Jin, R.D. (2012) Screening of Lead Resistant Microorganism and Preliminary Study on the Effect of Repairing Lead Polluted Soil by EDDS Chelating Induced Ryegrass. Journal of Jilin Agricultural Sciences, 37, 34-36. (In Chinese) http://dx.doi.org/10.7763/IJESD.2014.V5.516

[9] Aremu, M.O., Ogundola, A.K. and Emmanuel, O.T. (2013) Phytoextraction Potential of Vetiveria zizanioides on Heavy Metals. European Scientific Journal, 9, 1857-7431.

[10] Metwali, M.R., Gowayed, S.M.H., Al-Maghrabi, O.A. and Mosleh, Y.Y. (2013) Evaluation of Toxic Effect of Copper and Cadmium on Growth, Physiological Traits and Protein Profile of Wheat (Triticum aestivium L.), Maize (Zea mays L.) and Sorghum (Sorghum bicolor L.). World Applied Sciences Journal, 21, 301-314.

[11] Soudek, P., Petrová, Š., Vaňková, R., Song, J. and Vaněk, T. (2014) Accumulation of Heavy Metals Using Sorghum sp. Chemosphere, 104, 15-24. http://dx.doi.org/10.1016/j.chemosphere.2013.09.079

[12] Su, Y., Han, F.X., Sridhar, B.B.M. and Monts, D.L. (2005) Phytotoxicity and Phytoaccumulation of Trivalent and Hexavalent Chromium in Brake Fern. Environ Toxicol Chem, 24, 2019-2026. http://dx.doi.org/10.1897/04-329R.1

[13] Angelova, V.R., Ivanova, R.V., Delibaltova, A.V. and Ivanov, K.I. (2011) Use of Sorghum Crops for in Situ Phytoremediation of Polluted Soils. Journal of Agricultural Science and Technology A, 1, 693-702.

[14] Mohebbi, A. (2012) Capability of Heavy Metals Absorption by Corn, Alfalfa and Sunflower Intercropping Date Palm. Advances in Environmental Biology, 6, 2886-2893.

[15] Wang, J., Yang, N., Dong, E., Wang, L., Wu, A., Ding, Y., Bai, W. and Jiao, X. (2013) Effect of Different Plant Density on Growth, Yield and Nutrient Uptake of Sorghum. Chinese Agricultural Science Bulletin, 29, 253-258.

[16] Marchiol, L., Fellet, G., Perosa, D., Zaccheo, P. and Zerbi, G. (2010) Phytoremediation of Soils Polluted by Heavy Metals and Metalloids Using Crops: (ii) Early Results from the in Situ Experiment of Torviscosa (Udine). Italian Journal of Agronomy, 3, 15-29. http://dx.doi.org/10.4081/ija.2010.s2.15 